\title{
Hunting Poses Only a Low Risk for Alveolar Echinococcosis
}

\author{
Monika Wetscher ${ }^{1}$, Klaus Hackländer ${ }^{1}$, Viktoria Faber ${ }^{2}$, Ninon Taylor ${ }^{2+}$, Herbert Auer ${ }^{3}$ and \\ Georg G. Duscher ${ }^{4 *}$ \\ 1 Department of Integrative Biology and Biodiversity Research, Institute of Wildlife Biology and Game Management, University \\ of Natural Resources and Life Sciences, Vienna, Austria, ${ }^{2}$ Third Medical Department with Haematology, Medical Oncology, \\ Haemostaseology, Infectious Diseases and Rheumathology, Oncologic Center, Paracelsus Medical University, Salzburg, \\ Austria, ${ }^{3}$ Department of Medical Parasitology, Center of Pathophysiology, Infectiology and Immunology, Institute of Specific \\ Prophylaxis and Tropical Medicine, Medical University Vienna, Vienna, Austria, ${ }^{4}$ Department of Pathobiology, Institute of \\ Parasitology, University of Veterinary Medicine, Vienna, Austria
}

\section{OPEN ACCESS}

Edited by:

Olivier Vandenberg, LHUB-ULB, Belgium

Reviewed by: Aleksandra Barac, University of Belgrade, Serbia Bertrand Jacques Losson, University of Liege, Belgium

*Correspondence: Georg G. Duscher georg.duscher@vetmeduni.ac.at

${ }^{\dagger}$ Present Address: Ninon Taylor, Department of Dermatology, University Hospital Salzburg, Paracelsus Medical University, Salzburg, Austria

Specialty section: This article was submitted to Infectious Diseases - Surveillance, Prevention and Treatment, a section of the journal Frontiers in Public Health

Received: 17 January 2018 Accepted: 09 January 2019 Published: 29 January 2019

Citation:

Wetscher M, Hackländer K, Faber V,

Taylor N, Auer H and Duscher GG (2019) Hunting Poses Only a Low Risk

for Alveolar Echinococcosis.

Front. Public Health 7:7.

doi: 10.3389/fpubh.2019.00007
The Austrian province of Tyrol belongs to the areas where the alveolar echinococcosis (AE) caused by the fox tapeworm Echinococcus multilocularis (E. multilocularis) is highly endemic. In Central Europe and since 2011 in Austria, a growing incidence of human cases of $A E$ has been observed, presumably linked with increasing fox populations infected by the fox tapeworm E. multilocularis. Hunting and the related activities put hunters in a high-risk group, and they are considered particularly vulnerable for the contraction of an $\mathrm{AE}$. In light of this risk and the increased number of $\mathrm{AE}$ cases made public in Austria, the objective of the study was to investigate the prevalence of $A E$ in hunters and to provide a possible connection to the incidence increase. In 2015 and 2016, we examined 813 serums of active hunters from all nine districts of Tyrol and serologically tested them for E. multilocularis antibodies. Twenty-one (2.58\%) positive results in ELISA were detected via Western blot (WB), and only one $(0.12 \%)$ serum showed a low positive reaction. No lesion in the liver parenchyma could be detected by abdominal ultrasonography in this patient so far, but the risk of developing alveolar echinococcosis remains for this WB-positive hunter. Risk factor analysis of these 813 hunters revealed that 697 (85.7\%) hunted red foxes regularly and $332(40.8 \%)$ of those skinned them as well. Three hundred and eighteen (39.1\%) out of the 813 hunters were owners of hunting dogs; 89 (10.9\%) and 243 (29.9\%) were owners of non-hunting dogs and cats, respectively. Our results indicate that hunters do not have a greater risk of infection with E. multilocularis compared to non-hunters in Austria. The cause of the unexpected increase in AE cases in Austria remains unclear.

Keywords: Echinococcus multilocularis, active hunters, serological screening, risk factor, Austria

\section{INTRODUCTION}

Human alveolar echinococcosis (AE) is caused by the metacestode stage of the fox tapeworm Echinococcus multilocularis (1). In Central Europe, this rare parasitic disease that is potentially fatal in humans (2), primarily circulates within a sylvatic life cycle comprising red foxes (Vulpes vulpes) as definitive hosts and rodents (e.g., Microtus arvalis, Arvicola terrestris, Ondatra zibethica) as intermediate hosts $(3,4)$. The raccoon dog (Nyctereutes procyonoides) as neozoon species plays a similar role as the red fox as final host $(4,5)$. Also, pets, especially dogs, can also act as final hosts and contaminate the environment by excreting infective E. multilocularis eggs (6-10). Humans acquire the infection by peroral ingestion of 
E. multilocularis eggs present in contaminated soil, food, or animal skins $(6,11,12)$. Humans acquire the infection by peroral ingestion of E. multilocularis eggs present in contaminated soil, food, or animal skins $(6,11,12)$. The E. multilocularis metacestode in the intermediate host establishes itself primarily in the liver and shows a tumor-like growth pattern similar to a malignant tumor (13-15). Due to the prolonged growth of the parasite, the lack of specific symptoms in many cases, and the long incubation period of up to 20 years, AE is often diagnosed and treated in a rather late and metastatic stage (11, 16). Serological tests for detection of AE are available and allow early detection of disease before clinical manifestation $(1,17)$.

During recent decades the fox population increased due to successful rabies vaccination $(18,19)$. Hunting has repeatedly been published as a risk factor (20-24) and associated with AE acquisition (25). Further, there has been an increasing incidence of human AE cases in Austria, especially in the western provinces of Austria (Tyrol and Vorarlberg) (23). These increased AE cases were unexpected. Thus, it was recommended to improve the surveillance system in Austria by screening exposed individuals such as hunters, especially in E. multilocularis-endemic regions, to detect early AE cases (23).

To obtain data on the current situation regarding the aforementioned epidemiological development, we performed a serological study on anti-E. multilocularis antibodies comprising hunters of all nine Tyrolean districts in 2015 and 2016. This particular group was selected because of their potentially high exposure to eggs from infested foxes through their hunting activity, with the aim of quantifying human AE prevalence in hunters.

\section{MATERIALS AND METHODS}

\section{Study Area}

The study area is the province of Tyrol with its nine districts. Tyrol is bordered by the provinces of Salzburg to the east, Vorarlberg to the west, and Carinthia to the south. The neighboring countries of Tyrol are Germany (to the north), Italy (to the south), and Switzerland (to the west).

\section{Sample Collection}

The Hunting Association of Tyrol invited their members to participate at the annual meetings for the display of trophies in the capital cities of their districts. Out of 16,146 active hunters, 813 (i.e., 5\%, 736 males and 77 females) were willing in 2015 and 2016 to provide blood samples at these events.

Approval for this study was obtained from the Ethics Committee in Salzburg on January 28th, 2015 (No: 415-E/1845/22015). The written informed consent was given by the patients for their information to be stored and used for this study.

For demographic data and risk factors, each participant was also asked to complete a questionnaire concerning their hunting activity. The issues raised were temporal hunting activity, killing of red foxes, skinning of foxes as well as hunting dog ownership. Further questions concerned the ownership of pets such as dogs or cats.

The venous blood samples taken by medical doctors were performed using Vacuette ${ }^{\circledR}-$ Multiple Use Drawing Needle
(Greiner Bio-One GmbH. 4,550 Kremsmünster, Austria) and Vacuette ${ }^{\circledR}-8 \mathrm{ml}$ Z Serum Sep Clot Activator (Greiner Bio-One $\mathrm{GmbH}$. 4,550 Kremsmünster, Austria). The samples were stored at $+5^{\circ} \mathrm{C}$.

Serum tubes and questionnaires were numbered and checked twice by independent persons (medical doctors and a principal investigator) for their reliability.

\section{Serological Testing}

The analysis of the sera for anti-E. multilocularis antibodies was performed within $48 \mathrm{~h}$ at the Specific Prophylaxis and Tropical Medicine (SPTM). As a basic test, an enzyme-linked immunosorbent assay (ELISA) with E. multilocularis crude antigen was used (26). A commercial western blot (WB, LDBio, France) was used to confirm the positive results (27). Serum samples were considered serologically positive if they showed clearly positive reactions in the ELISA (cut-off: 20 Antibody Units based on a positive control serum with 100 AUs). Persons with positive antibody values were examined by WB and were informed by the principal investigator. In addition, they were asked to provide a further blood sample, and in the case of verification of positive test results, the participants were again personally contacted and ultrasound/computed tomography of the liver was recommended.

\section{Data Analysis}

All available details about age, hunting activities, pet ownership, and serological test were logged into an Excel spreadsheet (Microsoft Office Excel, Redmond, USA) and analyzed.

\section{RESULTS}

In total, 813 (736 males and 77 females) sera were evaluated during the 2 years human survey. The mean age of the hunters was 52.5 years and ranged from 18 to 86 . The age distribution was as follows: $4.7 \%$ were $18-25$ years old, $23.1 \%$ were $26-45$ years old, 44\% were 46-60 years old, and 28.2\% were older than 60 years of age. All of the participants had been hunting for, at least, 1 year, $26.6 \%$ for $2-10$ years and $20.8 \%$ for $11-20$ years, whereas $52.6 \%$ had been actively hunting for more than 20 years.

Out of 813 hunters, 697 (85.7\%) were regularly hunting red foxes, and $332(40.8 \%)$ of these also skinned foxes. About 318 (39.1\%) of the hunters had currently or in the recent past a hunting dog, and 89 (10.9\%) hunters owned a non-hunting dog. Cat ownership was reported among 243 (29.9\%) of the hunters (Table 1).

The serological analysis for antibodies against E. multilocularis antigen showed a low positive ELISA result in $21(2.6 \%$ participants) (Table 2 shows the hunting activities of the positive ELISA hunters), and one serum was positive by both ELISA and WB (Table 3). This serum originated from a male hunter from the district of Lienz (seroprevalence: $0.12 \%$ ), and the abdominal sonography showed no lesion changes in the liver parenchyma. This 80 years-old hunter was hunting for 62 years, shot and skinned foxes regularly, and had neither a hunting dog nor pets regularly. The real prevalence among the hunters in this cohort is 0 due to the lack of any confirmed AE case. 
TABLE 1 | Number of examined hunters in the nine Tyrolean districts, their hunting activities, and pet ownership.

\begin{tabular}{|c|c|c|c|c|c|c|c|c|}
\hline \multirow[t]{2}{*}{ District } & \multirow{2}{*}{$\begin{array}{c}n(\%) \\
\text { Examined } \\
\text { hunters }\end{array}$} & \multirow{2}{*}{$\begin{array}{c}n(\%) \\
\text { Shoot foxes }\end{array}$} & \multirow{2}{*}{$\begin{array}{c}n(\%) \\
\text { Skinning } \\
\text { foxes }\end{array}$} & \multirow{2}{*}{$\begin{array}{l}n(\%) \\
\text { Hunting dog } \\
\text { owner }\end{array}$} & \multirow{2}{*}{$\begin{array}{l}\text { Active hunting } \\
\text { period }^{\mathrm{a}}\end{array}$} & \multicolumn{3}{|c|}{$n(\%)$ ownership of pet } \\
\hline & & & & & & dog & cat & or both \\
\hline Innsbruck & 37 (4.6) & $28(4.0)$ & $13(3.9)$ & $12(3.8)$ & 17 & $6(6.7)$ & 8 (3.3) & $3(2.5)$ \\
\hline Innsbruck-Land & $98(12.1)$ & $84(12.1)$ & $30(9.0)$ & $32(10.1)$ & 21 & $8(9.0)$ & $27(11.1)$ & $11(9.2)$ \\
\hline Imst & $43(5.3)$ & $41(5.9)$ & $20(6.0)$ & $20(6.3)$ & 29 & $2(2.2)$ & $15(6.2)$ & $10(8.4)$ \\
\hline Kitzbühel & $98(12.1)$ & $92(13.2)$ & $49(14.8)$ & $32(10.1)$ & 26 & $16(18.0)$ & $31(12.8)$ & $13(10.9)$ \\
\hline Kufstein & $123(15.1)$ & $111(15.9)$ & $56(16.9)$ & $47(14.8)$ & 25 & $11(12.4)$ & $38(15.6)$ & $18(15.1)$ \\
\hline Landeck & $110(13.5)$ & $88(12.6)$ & $36(10.8)$ & $45(14.2)$ & 22 & $3(3.4)$ & $21(8.6)$ & $8(6.7)$ \\
\hline Lienz & $119(14.6)$ & $98(14.1)$ & $38(11.4)$ & $52(16.4)$ & 22 & $18(20.2)$ & $42(17.3)$ & $26(21.8)$ \\
\hline Reutte & $114(14.0)$ & 93 (13.3) & 47 (14.2) & 44 (13.8) & 22 & 21 (23.6) & 40 (16.5) & 22 (18.5) \\
\hline Schwaz & $71(8.7)$ & 62 (8.9) & $43(13.0)$ & $34(10.7)$ & 25 & $4(4.5)$ & 21 (8.6) & $8(6.7)$ \\
\hline Total & 813 (100.0) & 697 (85.7) & $332(40.8)$ & 318 (39.1) & 23 & 89 (10.9) & 243 (29.9) & 119 (14.6) \\
\hline
\end{tabular}

${ }^{a}$ Average of the active hunting period in years.

TABLE 2 | List of the 20 EmELISA positive hunters and their hunting activities and pet ownership.

\begin{tabular}{|c|c|c|c|c|c|c|c|c|c|c|c|c|c|c|c|c|c|c|c|c|c|}
\hline $\begin{array}{l}n \text { EmELISA } \\
\text { positive }\end{array}$ & 1 & 2 & 3 & 4 & 5 & 6 & 7 & 8 & 9 & 10 & 11 & 12 & 13 & 14 & 15 & 16 & 17 & 18 & 19 & 20 & $\sum$ \\
\hline Shoot foxes & $x$ & $x$ & $x$ & $x$ & $x$ & $x$ & $x$ & $x$ & & $x$ & $x$ & $x$ & $x$ & $x$ & $x$ & $x$ & $x$ & $x$ & $x$ & $X$ & 19 \\
\hline Skinning foxes & $X$ & $x$ & $x$ & & $x$ & & & & & $x$ & & $X$ & & $x$ & $x$ & & & $x$ & & & 9 \\
\hline Hunting dog owner & $x$ & & & & $x$ & & $x$ & & & & $x$ & $X$ & & $X$ & $x$ & $x$ & $x$ & $x$ & & & 10 \\
\hline Dog & & & & & & X & & & & & & & & & & & & & & & 1 \\
\hline Cat & & & & $x$ & & $x$ & $x$ & $x$ & & $x$ & $x$ & & $x$ & & & & & & & & 7 \\
\hline
\end{tabular}

Except the hunter with ELISA and WB positive findings, described separately.

TABLE 3 | Number of licensed and examined hunters in the nine Tyrolean districts and their serological test results.

\begin{tabular}{lcccc}
\hline District & $\begin{array}{c}\mathrm{a}_{\mathbf{n} \text { of }} \\
\text { hunters }\end{array}$ & $\begin{array}{c}\boldsymbol{n}(\%) \text { of } \\
\text { hunters } \\
\text { examined }\end{array}$ & $\begin{array}{c}\boldsymbol{n}(\%) \text { of } \\
\text { hunters } \\
\text { ELISA positive }\end{array}$ & $\begin{array}{c}\boldsymbol{n} \text { (\%) of } \\
\text { hunters } \\
\text { WB positive }\end{array}$ \\
\hline Innsbruck & 599 & $37(4.6)$ & 2 & 0 \\
Innsbruck-Land & 2.985 & $98(12.1)$ & 1 & 0 \\
Imst & 1.880 & $43(5.3)$ & 3 & 0 \\
Kitzbühel & 1.499 & $98(12.1)$ & 2 & 0 \\
Kufstein & 1.582 & $123(15.1)$ & 7 & 0 \\
Landeck & 1.988 & $110(13.5)$ & 1 & 0 \\
Lienz & 2.006 & $119(14.6)$ & 4 & 0 \\
Reutte & 1.262 & $114(14.0)$ & 0 & 0 \\
Schwaz & 2.345 & $71(8.7)$ & 1 & $1(0.12)$ \\
Total & 16.146 & $813(100.0)$ & $21(2.58)$ & \\
\hline
\end{tabular}

a Licensed hunters per district.

One of the 813 Tyrolean hunters (district Kitzbühel) had previously been treated successfully by surgical intervention (in-toto-extirpation of the parasite) in 2011. In our screening study, however, he presented a negative test result.

\section{DISCUSSION}

In the years 2015 and 2016, we tested the sera of 813 hunters from the province of Tyrol to evaluate the current situation of $\mathrm{AE}$ in the presumed risk group "hunters" originating from a highly endemic area $(1,7,13)$. However, $\mathrm{AE}$ is still a life-threatening disease for humans (11), but the prognosis is improved if the infection is diagnosed at a very early stage (even long before clinical manifestation). The serum sample of an 80 years-old hunter from the district of Lienz yielded a positive result by ELISA and by WB. In this case an infection with AE can be assumed and further confirmed by using ultrasound as the imaging screening method of choice (28). So far no visible lesions in the liver of this patient could be found. Thus, the hunter was instructed to repeat serological tests as well as ultrasound examination twice a year during the following years. In effect, liver lesions can take years to become apparent in seropositive persons (29), and lesions $<2 \mathrm{~cm}$ are difficult to diagnose (30). Due to its higher accuracy in detecting liver lesions [although without complete proof (31)], computerized tomography could be applied and was suggested but not carried out in this case, as this is the responsibility of the general practitioner.

Also, among another 20 hunters from all other districts (except in Reutte), low positive antibody levels could be determined, which could not be confirmed by WB. In these cases, it is necessary to carry out follow-up investigations to exclude an early stage of infection $(1,32)$, at least, once a year during the next 2 years $(17,29)$. Another explanation for this finding could be a cross-reaction in the ELISA (33). We can exclude E. granulosus in all 20 ELISA and WB positive E. multilocularis results by testing with indirect haemagglutination test (IHA) (26). 
Although 792 hunters (97.4\%) were serologically negative, documenting that they were not infected currently, all were strongly encouraged to re-examine their Echinococcus-immune status individually in intervals of 2-3 years, at least, during their active hunting period. The observation of seroconversion from negative to positive would demonstrate that a fresh infection must have occurred since the last examination.

If particularly exposed persons are regularly monitored by ultrasound imaging or by serological screenings (1, 34), the development of the slow-growing metacestode is rather limited and a cure becomes more likely. Hunters were considered as one of these risk groups (20-25) based on regular contact with foxes and pets $(6,35)$ as well as with contaminated fur (12) and environment.

In this study, $86 \%$ of hunters reported shooting foxes and $41 \%$ admitted to skinning foxes regularly. Also, 39\% keep hunting dogs and up to $30 \%$ are owners of dogs or cats as pets. Despite these high-hazard exposure potentials due to long hunting activities, as almost $52.6 \%$ had been hunting for more than 20 years, there was no clear evidence to make a diagnosis of AE. Similar to a study of trappers with high hunting activity in South Dakota, none of the trappers showed antibody evidence for the presence of E. multilocularis (36). In a case-control study from Tyrol, hunting was published as an independent risk factor in relation to $\mathrm{AE}$ (25). In contrast, (7) were not able to prove a connection between hunting and $\mathrm{AE}$ with double the number of test subjects in neighboring Germany. Different methods give differentiated statements about the risk of hunting; case-control studies increase the probability that hunting is a risk factor, but not significantly. This was shown in a recently published study in which case-control and cross-sectional studies were compared and no connection between hunting and $\mathrm{AE}$ Echinococcosis was proven (37). In south Gansu, China, a large number of AE cases was diagnosed using serological screening and ultrasonography, and hunting had no effect as a risk factor (38). A total of 23,321 people were examined in three published serological screening studies in Austria $(21,39,40)$. Two AE cases could be diagnosed with this preventive screening examination; both cases occurred in the province of Tyrol and had no connection to hunting. Given these results, we assume that hunters are not at a higher risk of contracting an $\mathrm{AE}$ than non-hunters. Furthermore, the increase in confirmed AE cases in Austria could not be ascribed to hunting due to a lack of available data on occupation and leisure activities (23). The study of 149 (100\%) hunters in southeastern Austria showed 7 (5\%) subjects with a positive ELISA value and none could be confirmed in WB (21). In our studies, with a 5.5 times higher number of test subjects, there were 2.6 and $0.12 \%$, ELISA and WB, respectively, positive results. The ELISA reactions show that increased contact with E. multilocularis eggs (41) takes place due to hunting. In healthy individuals, however, only a low level of manifestation takes place and an $\mathrm{AE}$ is prevented (42). In contrast, a weakened immune system promotes infection of E. multilocularis in humans $(43,44)$ and significantly increases the risk of contracting $\operatorname{AE}(45,46)$. In the course of this study, we tested one individual whose AE liver lesion was surgically removed in 2011. The lack of antibodies in this subject is presumably due to the success of the surgery
(47). Furthermore, it should be mentioned that this test subject suffered from cancer and had immunosuppressive therapy beforehand.

Studies show that pets, dogs, and cats excrete infectious $E$. multilocularis eggs $(6,8-10)$. The case-control study from Tyrol, in which hunting poses a risk, also showed a connection between cats and AE in western Austria (25). In this single case-control study in Austria, dog ownership was reported as a low-risk factor. In contrast, another case-control study showed dog ownership, especially where the dogs spend a lot of time outdoors, as a major risk factor (7). An increase in human seroprevalence was reported in an area with a high prevalence of E. multilocularis in intermediate hosts (rodents) and prevalence detection of $E$. multilocularis in domestic animals, however, without an increase in human $\mathrm{AE}$ cases (48). In our study, $69 \%$ of test subjects had a hunting dog as well as dogs and cats as pets. The potential risk of infection is unknown in Austria, as there is no data on the prevalence of E. multilocularis in dogs and cats. Our study shows that despite considerable possession of hunting dogs and pets, no $\mathrm{AE}$ was diagnosed in the risk group of hunters.

To summarize, the results indicate that hunters come into contact with E. multilocularis, which was ascertained by positive ELISA and WB tests. However, thus far, we have not been able to observe that the proportion of hunters is higher than the proportion of non-hunters among all Austrian AE patients. The unexpected AE cases in Austria could not be explained with our investigations of an exposed group of "hunters." This study demonstrates the need for further research to elucidate on conflicting results and identify the actual risk factors for AE to be able to avoid preventable AE illnesses. Missing data, especially in pets about the prevalence rates of E. multilocularis in Austria, should be investigated in future.

\section{ETHICS STATEMENT}

This study was carried out in accordance with the recommendations of the Ethics Committee in Salzburg. All subjects gave written informed consent in accordance with the Declaration of Helsinki. The protocol was approved by the Ethics Committee in Salzburg on January 28th, 2015. 415-E/1845/2-2015.

\section{AUTHOR CONTRIBUTIONS}

MW designed the study. MW and VF were responsible for taking blood samples. MW, KH, HA, VF, NT, and GD all contributed to the manuscript editing and approved the final version of this manuscript.

\section{ACKNOWLEDGMENTS}

We thank the Tyrolean hunting association (Tiroler Jägerverband) for financial support to conduct this study. We also appreciate all the Tyrolean hunters for their participation in this project. Also, we wish to thank Ina Kandil, Walburga Maderthaner, Sabine Rosenlechner, Michael Rosenlechner, and Michaela Schachner. 


\section{REFERENCES}

1. Auer H. Die Bedeutung labordiagnostischer Untersuchungen für die Klinik, die Epidemiologie und Prävention der alveolären Echinokokkose Erfahrungen zweier Jahrzehnte in Österreich. [Relevance of parasitological examinations for the clinical course, epidemiology and prevention of alveolar echinococcosis - experiences of more than two decades in Austria]. Wien. Klin. Wochenschr. (2006) 118 (Suppl 3):18-26. doi: 10.1007/s00508-006-0673-3

2. Piarroux M, Piarroux R, Giorgi R, Knapp J, Bardonnet K, Sudre B, et al. Clinical features and evolution of alveolar echinococcosis in France from 1982 to 2007: results of a survey in 387 patients. J Hepatol. (2011) 55:1025-33. doi: 10.1016/j.jhep.2011.02.018

3. Eckert J, Deplazes P, Craig PS, Gemmell MA, Gottstein B, Heath D, et al. Echinococcosis in animals: clinical aspects, diagnosis and treatment. In: Eckert J, Gemmell MA, Meslin FX, Pawlowski Z, editors. WHO/OIE Manual on Echinococcosis in Humans and Animals. Courtesy of the Institute of Parasitology, University of Zurich (2001). p. 73-99.

4. Oksanen A, Siles-Lucas M, Karamon J, Possenti A, Conraths FJ, Romig $\mathrm{T}$, et al. The geographical distribution and prevalence of Echinococcus multilocularis in animals in the European Union and adjacent countries: a systematic review and meta-analysis. Parasit Vectors (2016) 9:519. doi: 10.1186/s13071-016-1746-4

5. Duscher T, HodŽić A, Glawischnig W, Duscher GG. The raccoon dog (Nyctereutes procyonoides) and the raccoon (Procyon lotor) - their role and impact of maintaining and transmitting zoonotic diseases in Austria, Central Europe. Parasitol Res. (2017) 116:1411-1416. doi: 10.1007/s00436-017-5405-2

6. Eckert J, Deplazes P. Biological, epidemiological, and clinical aspects of echinococcosis, a zoonosis of increasing concern. J Clin Microbiol Rev. (2004) 17:107-35. doi: 10.1128/CMR.17.1.107-135.2004

7. Kern P, Ammon A, Kron M, Sinn G, Sander S, Petersen LR, et al. Risk factors for alveolar echinococcosis in humans. Emerg Infect Dis. (2004) 10:2088-93. doi: 10.3201/eid1012.030773

8. Duscher GG, Leschnik M, Fuehrer HP, Joachim A. Wildlife reservoirs for vector-borne canine, feline and zoonotic infections in Austria. Int J Parasitol Parasit Wildl. (2015) 4:88-96. doi: 10.1016/j.ijppaw.2014.12.001

9. Karamon J, Samorek-Pieróg M, Kochanowski M, Dabrowska J, Sroka J, Gołab E, et al. First detection of Echinococcus multilocularis in dogs in a highly endemic area of Poland. Folia Parasitol. (2016) 63:2016.018. doi: 10.14411/fp.2016.018

10. Bastien M, Vaniscotte A, Combes B, Umhang G, Germain E, Gouley V, et al. High density of fox and cat faeces in kitchen gardens and resulting rodent exposure to Echinococcus multilocularis and Toxoplasma gondii. Folia Parasitol. (2018) 65:2018.002. doi: 10.14411/fp.2018.002

11. Brunetti E, Kern P, Vuitton DA, Writing Panel for the WHO.IWGE. Expert consensus for the diagnosis and treatment of cystic and alveolar echinococcosis in humans. Acta Trop. (2010) 114:1-16. doi: 10.1016/j.actatropica.2009.11.001

12. Nagy A, Ziadniov I, Schweiger A, Schnyder M, Deplazes P. Fellkontamination mit Eiern von zoonotischen Helminthen bei Hof- und Haushunden sowie bei Füchsen. [Hair coat contamination with zoonotic helminth eggs of farm and pet dogs and foxes]. Berl Munch Tierarztl Wschr. (2011) 124:503-11.

13. Kern P, Bardonnet K, Renner E, Auer H, Pawlowski Z, Ammann RW, et al. European echinococcosis registry: human alveolar echinococcosis, Europe, 1982-2000. Emerg Infect Dis. (2003) 9:343-9. doi: 10.3201/eid0903.020341

14. Tsaroucha AK, Polychronidis AC, Lyrantzopoulos N, Pitiakoudis MS, Karayiannakis AJ, Manolas KJ, et al. Hydatid disease of the abdomen and other locations. World J Surg. (2005) 29:1161-5. doi: 10.1007/s00268-005-7775-3

15. Ricken FJ, Nell J, Grüner B, Schmidberger J, Kaltenbach T, Kratzer W, et al. Albendazole increase the inflammatory response and the amount of Em2-positive small particles of Echinococcus multilocularis (spems) in human hepatic alveolar echinococcosis lesions. PLoS Negl Trop Dis. (2017) 11:e0005636. doi: 10.1371/journal.pntd.0005636

16. Goetz M, Hainz M, Schadmand-Fischer S, Kittner JM, Heinrich S. Echinococcosis mimicking autoimmune or malignant bile duct disease. Gastroenterol (2013) 51:1089-91. doi: 10.1055/s-0033-1335751

17. Bartholomot B, Vuittin AD, Harraga S, Shi DZ, Giraudoux P, Barnish G, et al. Combined ultrasound and serologic screening for hepatic alveolar echinococcosis in central China. Am J Trop Med Hyg. (2002) 66:23-9. doi: 10.4269/ajtmh.2002.66.23

18. Duscher G, Pleydell D, Pros LH, Joachim A. Echinococcus multilocularis in Austrian foxes from 1991 until 2004. J Vet Med B (2006) 53:138-44. doi: 10.1111/j.1439-0450.2006.00930.x

19. Schweiger A, Ammann RW, Candinas D, Clavien PA, Eckert J, Gottstein B, et al. Human alveolar echinococcosis after fox population increase, Switzerland. Emerg Infect Dis. (2007) 13:878-82. doi: 10.3201/eid1306. 061074

20. Eckert J. Echinococcus multilocularis in Europa - Versuch einer Risikobewertung. [Echinococcus multilocularis in Europe: an attempt to assess the risk]. Mitt Österr Ges Tropenmed Parasitol. (1996) 18:131-40.

21. Deutz A, Fuchs K, Schuller W, Nowotny N, Auer H, Aspöck $\mathrm{H}$, et al. Seroepidemiologische Untersuchung von Jägern in Südostösterreich - Prävalenzen, Risikopotentiale und Vorbeugemaßnahmen [Seroepidemiological studies of zoonotic infections in hunters in southeastern Austria - prevalences, risk factors and preventive methods]. Berl Munch Tierarztl Wschr. (2003) 116:306-11.

22. Tiaoying L, Jiamin Q, Wen Y, Craig PS, Xingwang C, Ning X, et al. Echinococcosis in Tibetan populations, Western Sichuan, province, China. Emerg Infect Dis. (2005) 11:1866-73. doi: 10.3201/eid1112.050079

23. Schneider R, Aspöck H, Auer H. Unexpected increase of alveolar echinococcosis, Austria, 2011. Emerg Infect Dis. (2013) 19:475-7. doi: $10.3201 /$ eid1903.120595

24. Sadkowska-Todys M, Baumann-Popczyk A, Wnukowska N, Popczyk B, Kucharczyk B, Golab E. Occurrence and prevalence of selected zoonotic agents: echinococcus multilocularis, Trichinella spiralis and hepatitis E virus (HEV) in the population of Polish hunters - results of the study conducted in 2010-2012. Przegl Epidemiol. (2015) 69:673-8.

25. Kreidl P, Allerberger F, Judmaier G, Auer H, Aspöck H, Hall AJ. Domestic pets as risk factors for alveolar hydatid disease in Austria. Am J Epidemiol. (1998) 147:978-81.

26. Auer $\mathrm{H}$, Picher $\mathrm{O}$, Aspöck $\mathrm{H}$. Combined application of enzyme-linked immunosorbent assay (ELISA) and indirect haemagglutination test (IHA) as a useful tool for the diagnosis and post-operative surveillance of human alveolar and cystic echinococcosis. Zbl Bakt Hyg A (1988) 270:313-25.

27. Liance M, Janin V, Bresson-Hadni S, Vuitton DA, Houin R, Piarroux R. Immunodiagnosis of Echinococcus infections: confirmatory testing and species differentiation by a new commercial western blot. J Clin Microbiol. (2000) 38:3718-21.

28. Mihmanli M, Idiz UO, Kaya C, Demir U, Bostanci O, Omeroglu S, et al. Current status of diagnosis and treatment of hepatic echinococcosis: World J Hepatol. (2016) 8:1169-81. doi: 10.4254/wjh.v8.i28.1169

29. Jensen B, Reuter S, Kratzer W, Naser K, Kächele V, Kimmig P, et al. Long term seropositivity against Echinococcus multilocularis in an epidemiological follow-up study in Southwestern Germany (Römerstein). Infection (2001) 29:310-14. doi: 10.1007/s15010-001-1153-3

30. Liu W, Delabrousse E, Blagosklonov O, Wang J, Zeng H, Jiang Y, et al. Innovation in hepatic alveolar echinococcosis imaging: best use of old tools and necessary evaluation of new ones. Parasite (2014) 21:1-14. doi: $10.1051 /$ parasite/2014072

31. Reuter S, Nüssle K, Kolokythas O, Haug U, Rieber A, Kern P, et al. Alveolar liver echinococcosis: a comparative study of three imaging techniques. Infection (2001) 29:119-25. doi: 10.1007/s15010-001-1081-2

32. Bresson-Hadni S, Laplante JJ, Lenys D, Rohmer P, Gottstein B, Jacquier P, et al. Seroepidemiologic screening of Echinococcus multilocularis infection in a European area endemic for alveolar echinococcosis. Am J Trop Med Hyg. (1994) 51:837-46. doi: 10.4269/ajtmh.1994.51.837

33. Gottstein B, Jacquier P, Bresson-Hadni S, Eckert J. Improved primary immunodiagnosis of alveolar echinococcosis in humans by an enzyme-linked immunosorbent assay using the Em2Plus antigen. J Clin Microbiol. (1993) 13:373-6.

34. Romig T, Kratzer W, Kimmig P, Frosch M, Gaus W, Flegel WA, et al. An epidemiologic survey of human alveolar echinococcosis in southwestern Germany. Römerstein Study Group. Am J Trop Med Hyg. (1999) 61:566-73.

35. Craig PS. Epidemiology of human alveolar echinococcosis in China. Parasitol Int. (2006) 55:221-5. doi: 10.1016/j.parint.2005.11.034 
36. Hildreth MB, Sriram S, Gottstein B, Wilson M, Schantz PM. Failure to identify alveolar echinococcosis in trapper from South Dakota in spite of high prevalence of Echinococcus multilocularis in wild canids. J Parasitol. (2000). 86:75-7. doi: 10.1645/0022-3395(2000)086[0075:FTIAEI]2.0.CO;2

37. Conraths FJ, Probst C, Possenti A, Boufana B, Saulle R, La Torre G, et al. Potential risk factors associated with human alveolar echinococcosis: systematic review and meta-analysis. PLOS Negl Trop Dis. (2017) 11:1-15. doi: 10.1371/journal.pntd.0005801

38. Craig PS, Giraudoux P, Shi D, Bartholomot B, Barnish G, Delattre $\mathrm{P}$, et al. An epidemiological and ecological study of human alveolar echinococcosis transmission in south Gansu, China. Acta Trop. (2000) 77:167-77. doi: 10.1016/S0001-706X(00)00134-0

39. Auer H, Schönitzer D, Judmaier G, Conrad F, Aspöck H. Seroepidemiologisches Screening als Grundlage präventivmedizinischer Maßnahmen zur Früherkennung der alveolären Echinokokkose. [Seroepidemiologic screening as a tool for the early detection of alveolar echinococcosis]. Mitt Österr Ges Tropenmcd Parasitol. (1995) 17:77-84.

40. Poeppl W, Herkner H, Tobudic S, Faas A, Mooseder G, Burgmann H, Auer H. Exposure to Echinococcus multilocularis, Toxocara canis, and Toxocara cati in Austria: a nationwide cross-sectional seroprevalence study. Vector Borne Zoonot Dis. (2013) 13:798-803. doi: 10.1089/vbz. 2012.1283

41. Beldi G, Müller N, Gottstein B. [Die alveoläre Echinokokkose]. Swiss Med Forum (2017) 17:760-66. doi: 10.4414/smf.2017.03046

42. Vuitton DA, Gottstein B. Echinococcus multilocularis and its intermediate host: a model of parasite-host interplay. J Biomed Biotechnol. (2010) 2013:923193. doi: 10.1155/2010/923193

43. Vuitton DA, Zhang SL, Yang Y, Godot V, Beurton I, Mantion G, et al. Survival strategy of Echinococcus multilocularis in the human host. Parasitol Intern. (2006) 55:51-5. doi: 10.1016/j.parint.2005.11.007

44. Noormahomed EV, Nhacupe N, Mascaró-Lazcano C, Mauaie MN, Buene T, Funzamo CA, et al. A cross-sectional serological study of cysticercosis, schistosomiasis, toxocariasis and echinococcosis in HIV-1 infected people in Beira, Mozambique. PLoS Negl Trop Dis. (2014) 8:e3121. doi: 10.1371/journal.pntd.0003121

45. Chauchet A, Grenouillet F, Knapp J, Richou C, Delabrousse E, Dentan $\mathrm{C}$, et al. Increased incidence and characteristics of alveolar echinococcosis in patients with immunosuppression-associated conditions. Clin Infect Dis. (2014) 59:1095-104. doi: 10.1093/cid/ciu520

46. Vuitton DA, Demonmerot F, Knapp J, Richou C, Grenouillet F, Chauchet A, et al. Clinical epidemiology of human AE in Europe. Vet Parasitol. (2015) 213:110-20. doi: 10.1016/j.vetpar.2015. 07.036

47. Wen H, Bresson-Hadni S, Vuitton DA, Lenys D, Yang BM, Ding ZX, et al. Analysis of immunoglobulin $\mathrm{G}$ subclass in the serum antibody responses of alveolar echinococcosis patients after surgical treatment and chemotherapy as an aid to assessing the outcome. Trans R Soc Trop Med Hyg. (1995) 89:692-7. doi: 10.1016/0035-9203(95)90449-2

48. Gottstein B, Saucy F, Deplazes P, Reichen J, Demierre G, Busato A, et al. Is high prevalence of Echinococcus multilocularis in wild and domestic animals associated with disease incidence in humans? Emerg Infect Dis. (2001) 7:40812. doi: 10.3201/eid0703.017307

Conflict of Interest Statement: The authors declare that the research was conducted in the absence of any commercial or financial relationships that could be construed as a potential conflict of interest.

Copyright (C) 2019 Wetscher, Hackländer, Faber, Taylor, Auer and Duscher. This is an open-access article distributed under the terms of the Creative Commons Attribution License (CC BY). The use, distribution or reproduction in other forums is permitted, provided the original author(s) and the copyright owner(s) are credited and that the original publication in this journal is cited, in accordance with accepted academic practice. No use, distribution or reproduction is permitted which does not comply with these terms. 